\title{
Nostalgia Instruction Enhances the Subjective Well-Being of Undergraduates
}

\author{
Xiaoli Tao \\ School of Education \\ Zhanjiang Normal University \\ Guangdong,China \\ sunnytao79@gmail.com \\ Hongge Liang \\ School of Education \\ Zhanjiang Normal University \\ Guangdong,China
}

\author{
Huiming Zeng \\ School of Education \\ Zhanjiang Normal University \\ Guangdong,China
}

\begin{abstract}
Nostalgia is recognized as an emotional experience that enables the integration of the past with the present. In this study, 396 undergraduate students were assigned randomly to either a nostalgia instruction group or a control group (in which they recall ordinary things). The life satisfaction and subjective well-being of the participants were measured in the experiment. The results indicated that the participants in the nostalgia group produced a larger number of positive words and fewer neutral and negative words compared with the participants in the control group. Thus, nostalgic instruction increased their life satisfaction and well-being. These findings suggested that nostalgic instruction could be an effective psychological resource for undergraduates, and that nostalgia results in a combination of positive, neutral, and negative effects.
\end{abstract}

Keywords-Nostalgia, Positive Emotion, Life Satisfaction, Subjective Well-being, Undergraduate Students

\section{INTRODUCTION}

Autobiographical memories are commonly associated with emotions, times, and places, and can be stated explicitly. Nostalgia is a sentimental longing or wistful affection for experiences that are vividly remembered. In this sense, nostalgia is a type of social emotion [1]. Several incidents can trigger nostalgia, such as when people feel sad and alone, or when they listen to music [2]. People tend to feel more nostalgic when the weather is cold [3].

Although nostalgia is associated with depression, sadness, and homesickness [4], other studies support the view that positivity and happiness result from nostalgic experience [4, 5]. Wildschut et al. (2004) propose the existential function of nostalgia, and believe that nostalgia strengthens social bonds and increases perceived social support, such as love, honor, and protectiveness [6]

Nostalgia can promote the subjective well-being of people who experience it [7]. The influence of nostalgia on human behavior is reflected in advertisements and consumer behavior. Nostalgia increases positive moods and self-esteem, and releases the anxiety experienced in life and related to death [8]. Moreover, nostalgia is a psychological resource that fosters mental health [9], and a positive resource for the self [8]. The findings of Zhou et al. (2012) indicate that nostalgic instruction motivates participants to donate more money or time compared with participants in the control group [1]. Nostalgia improves the attitudes toward overweight persons [10].

Previous studies report how nostalgic memories can be pleasant, and beneficial to the subjective well-being of people. People feel more warmth and happiness when they experience nostalgia [11]. Nostalgia arouses positive emotions and promotes positive attitudes. These emotions in nostalgic experiences are warmth, appreciation, and happiness [3]. Wildschut et al. (2006) claims nostalgia contributes to the well-being of participants. However, empirical research linking nostalgia to the life satisfaction and subjective well-being of undergraduate students is relatively scarce. Limited research has been conducted on the emotional content of nostalgic instruction.

This study has two main objectives. First, this research explores the emotional content of the nostalgic instruction effect via emotional content analyses of four nostalgic keywords written by the participants in the experiment. Second, this study investigates whether nostalgic instructions have a positive influence on the life satisfaction and subjective well-being of undergraduates compared with participants in a control group (i.e., participants who recall ordinary events).

\section{METHODS}

\section{Participants}

We recruited 396 undergraduate students from the Zhangjiang Normal University (109 men and 287 women). Their ages ranged from 17 to 24 years old $(M=20.37, S D$ =1.36). The participants were randomly assigned to the nostalgia group (199 participants, 55 men, and 144 women) or the control group (197 participants, 54 men, and 143 women). Nineteen participants (10 in the nostalgia group and 9 in the control group) were disqualified for their invalid questionnaires. 


\section{Materials}

To make the participants in the first group experience nostalgia, we induced nostalgic thoughts through the manipulation method used by Wildschut et al. (2006) and Zhou et al. (2011). The participants in the nostalgia group read the following instructions:

Recall nostalgic events in your life. Specifically, try to think of a past event that made you feel most nostalgic. Take a few moments to think about the nostalgic event, and how it made you feel. Then, list your feelings in four keywords.

In the control group, the participants read the following instructions:

Recall ordinary events in your life, such as those events that took place in the past month. Take a few moments to think about the ordinary event, and how it made you feel. Then, list your feelings in four keywords.

Thereafter, the participants were asked to complete a validated manipulation check (Wildschut et al., 2006). The participants rated on a scale of 1 (strongly disagree) to 7 (strongly agree) this item, "Right now, I am feeling quite nostalgic." Then, the participants responded to two filler questionnaires, including the general subjective well-being scale (Andrews \& Withey 1976) and the satisfaction with life scale [12]. High scores reflect higher levels of subjective well-being and life satisfaction. All the materials were printed on both sides of A4 size paper, and were sent to participants in the classroom.

\section{Procedure}

We presented all the materials in a single printed booklet. The participants were asked to complete the questionnaire carefully, and to check if certain items were neglected.

\section{RESULTS}

\section{A. Manipulation check and emotional content of nostalgia}

As predicted, the participants in the nostalgia group reported feeling more nostalgic $(\mathrm{M}=5.63)$ than the participants in the control group $(\mathrm{M}=5.05), \mathrm{t}(375)=4.57$, $\mathrm{p}<0.0001$. The four keywords written by all the participants were assessed from the category of emotion by two raters. The coefficient of concordance was 0.821 (positive words), 0.826 (neutral words), and 0.897 (negative words). The participants in the nostalgia group wrote more positive words $(\mathrm{M}=2.81)$ than the participants in the control group $(\mathrm{M}=1.49), \mathrm{t}(375)=10.679, \mathrm{p}<$ 0.0001. Meanwhile, the participants in the nostalgia group wrote fewer neutral (0.63) and negative words (0.56) compared with the participants in the control group $(0.84$, $1.66), \mathrm{t}(375)=-2.068, \mathrm{p}<0.05, \mathrm{t}(375)=-10.04, \mathrm{p}<$ 0.0001 (see Fig. 1).
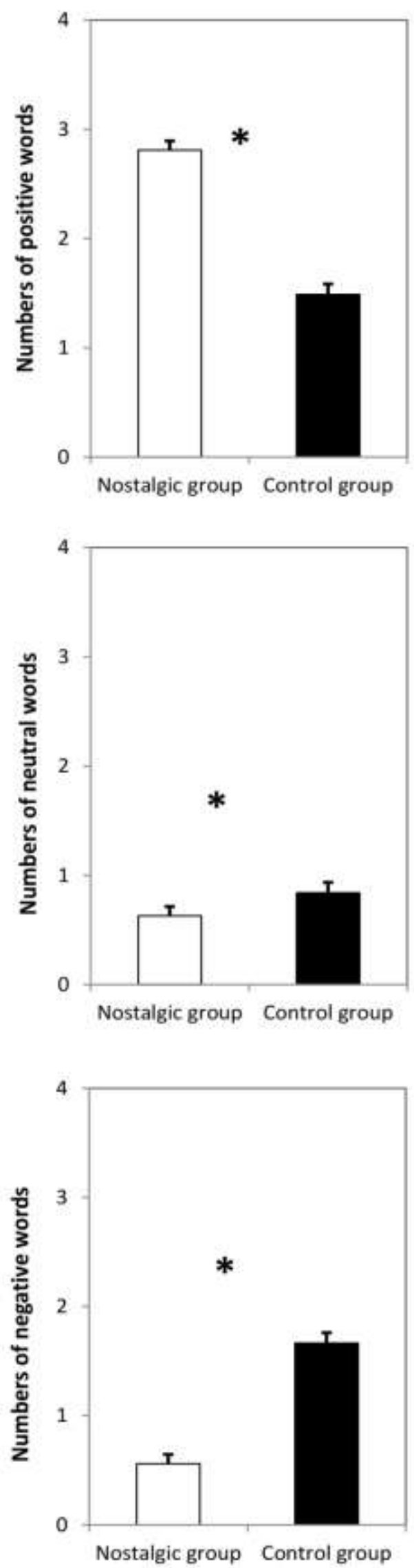

Figure 1. Results of the emotional content analyses of nostalgia 


\section{B. Effect of nostalgic instruction on life satisfaction and subjective well-being}

The life satisfaction scores of the two groups differed significantly. The participants in the nostalgia group showed higher scores $(\mathrm{M}=3.69)$ than participants in the control group $(\mathrm{M}=3.19), \mathrm{t}(375)=4.874, \mathrm{p}<0.0001$. Taking the score of the subjective well-being scale as an independent variable, we observed a robust difference between participants in the nostalgia and control groups. The participants in the nostalgia group showed more subjective well-being $(M=4.31)$ than the participants in the control group $(\mathrm{M}=4.07), \mathrm{t}(375)=2.098, \mathrm{p}<0.05$ (see Fig. 2).
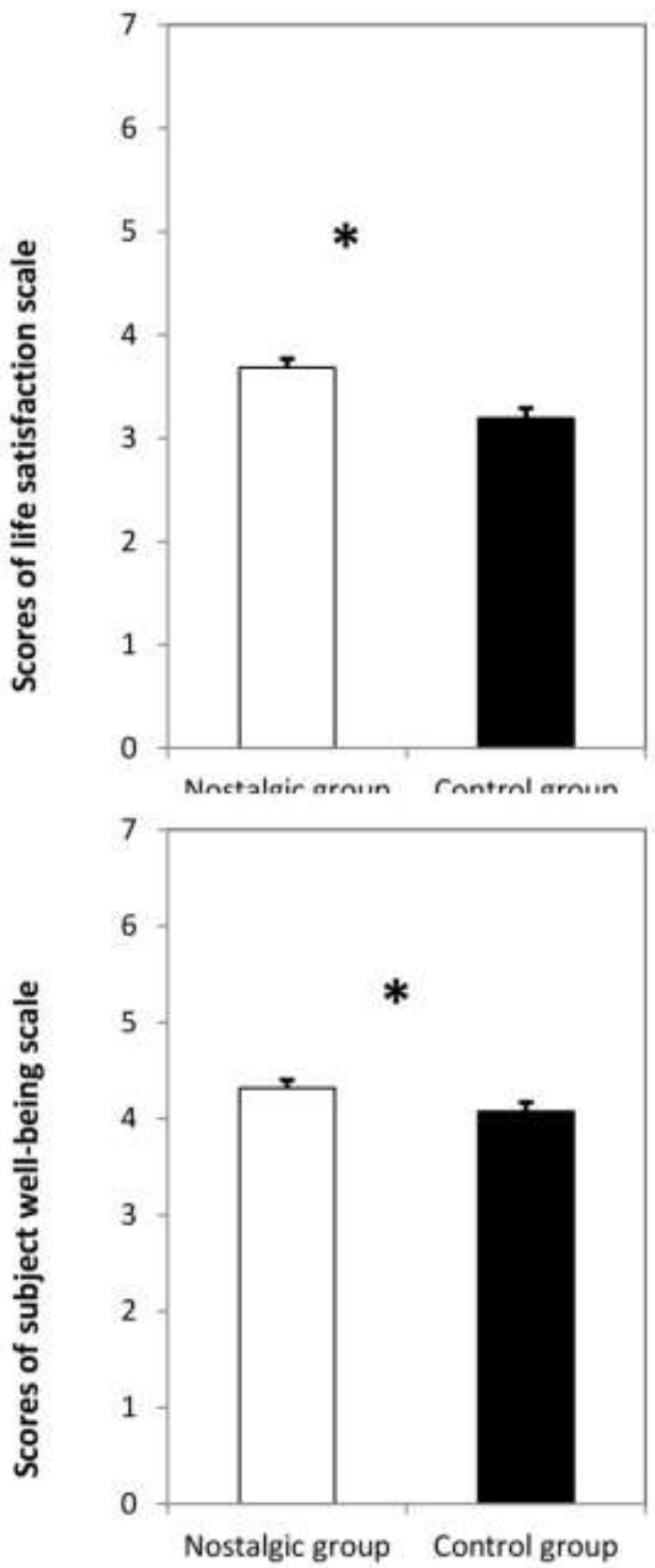

Figure 2. Effect of nostalgic instruction on satisfaction and subjective well-being scores

\section{DISCUSSION}

This study explores the influence of nostalgic instruction on the life satisfaction and subjective well- being of undergraduate students. The results indicate that the participants in the nostalgia group had higher scores in life satisfaction and subjective well-being than the participants in the control group. The content analysis shows that compared with the control group participants who recalled ordinary events, the participants in the nostalgia group wrote more positive words and fewer neutral and negative words. These findings suggest that nostalgia could serve as a psychological resource that might enable undergraduates to adjust their emotional states.

Nostalgia improves the life satisfaction and subjective well-being of undergraduates. The results of the present study are consistent with Pourtova (2013), who claim that nostalgia was a kind of emotional experience that could integrate the past and the present. Sedikides et al. (2004) regard nostalgia as a positive emotion. Moreover, nostalgia involves a contrast between the present and the past Routledge et al (2011) report that nostalgia, by changing the emotional state of a person, could maintain psychological balance and reduce unhappiness caused by interpersonal exclusion. Attachment to security and social connections helps people to understand the feelings of others, and enables them to recall more things that are positive.

Consistent with previous works (e.g., Hepper et al.,2006), this study suggests nostalgia is oriented by positive emotions[13]. This observation is indicated in the writing of more positive words and fewer neutral and negative words of the participants in the nostalgia group. The positive emotions, negative emotions, or a combination of both types could arise after listening to nostalgic music with lyrics that are characterized by bittersweet reverie[14]. Related analysis demonstrates that the number of positive words written by the participants positively related to their life satisfaction and subjective well-being scores, whereas the number of negative words written by the participants was negatively related to those scores. According to Holak and Havlena(1992), nostalgia is a kind of complex emotion that involves happy and pleasant feelings as well as sad emotions about the past [15]. Nostalgia is a significant control mechanism that could increase life satisfaction by decreasing the unhappiness caused by language and cultural differences and by increasing peaceful and pleasant feelings[16] Nostalgia helps people to experience satisfaction, to see the beauty of life again, to reduce the fear of death, to mitigate loneliness and feelings related to negative life experiences, and to consider life more meaningful[17].

\section{CONCLUSIONS}

Our findings show nostalgic instruction motivated the participants to produce a larger number of positive words, and increased their life satisfaction and subjective wellbeing. The results of our study suggest that nostalgia can serve as an effective psychological resource for undergraduates.

\section{ACKNOWLEDGMENT}

This research was supported by grants from Foundation for Distinguished Young Talents in Higher Education of Guangdong, China(2012 WYM_0092) and 


\section{Foundation of Doctor Project in Zhanjiang Normal} University (Z11203).

\section{REFERENCES}

[1]Zhou, X., et al., Nostalgia: the gift that keeps on giving[J]. Journal of Consumer Research, 2012. 39(1): p. 39-50.

[2]Barrett, F.S., et al., Music-Evoked Nostalgia: Affect, Memory, and Personality[J]. Emotion, 2010. 10(3): p. 390-403.

[3]Zhou, X., et al., Heartwarming Memories: Nostalgia Maintains Physiological Comfort. Emotion, 2012. 12(4): p. 678-684.

[4]Sedikides, C., T. Wildschut and D. Baden, Nostalgia, Conceptual Issues and Existential Functions, in Handbook of Experimental Existential Psychology[M]. 2004, The Guilford Press, A Division of Guilford Publications: New York, NY. p. 200-213.

[5]Batcho, K.I., Personal nostalgia, world view, memory, and emotionality[J]. Perceptual and motor skills, 1998. 87(2): p. 411-32.

[6]Constantine, S., et al., Nostalgia Past, Present, and Future[J]. Current Directions in Psychological Science, 2008. 17(5): p. 304-307.

[7]Wildschut, T., et al., Nostalgia: Content, triggers, functions[J]. Journal of Personality and Social Psychology, 2006. 91(5): p. 975993.

[8]Vess, M., et al., Nostalgia as a Resource for the Self[J]. Self and Identity, 2012. 11(3): p. 273-284
[9]Zhou, X., et al., Counteracting Loneliness: On the Restorative Function of Nostalgia[J]. Psychological Science, 2008. 19(10): p 1023-1029.

[10]Turner, R.N., T. Wildschut and C. Sedikides, Dropping the weight stigma: Nostalgia improves attitudes toward persons who are overweight[J]. Journal of Experimental Social Psychology, 2012. 48(1): p. 130-137.

[11]Routledge, C., et al., The power of the past: Nostalgia as a meaningmaking resource[J]. Memory, 2012. 20(5): p. 452-460.

[12]Diener, E., et al., The satisfaction with life scale. Journal of Personality Assessment, 1985(49): p. 71-75.

[13]Hepper, E.G., et al., Odyssey's End: Lay Conceptions of Nostalgia Reflect Its Original Homeric Meaning[J]. Emotion, 2012. 12(1): p. 102-119.

[14]Batcho, K.I., Nostalgia and the emotional tone and content of song lyrics[J]. American Journal of Psychology, 2007. 120(3): p. 361381

[15]. Susan, L.H. and J.H. William, Nostalgia: an Exploratory Study of Themes and Emotions in the Nostalgic Experience [J]. Advances in Consumer Research, 1992. 1(19): p. 380-387.

[16]. Dickinson, H. and M. Erben, Nostalgia and Autobiography: The Past in the Present [J]. Auto/Biography, 2006. 3(14): p. 223-244.

[17]. Routledge, C., et al., The Past Makes the Present Meaningful: Nostalgia as an Existential Resource [J]. Journal of personality and social psychology, 2011. 101(3): p. 638-652. 